\title{
Interpretação Ambiental à luz dos princípios da Análise do Comportamento: contribuições para Educação Ambiental
}

\section{Environmental Interpretation based on the principles of Behavior Analysis: contributions to Environmental Education}

\author{
Interpretación Ambiental a la luz de los principios del Análisis del \\ Comportamiento: contribuciones a la Educación Ambiental
}

\section{Diego Marques da Silva Medeiros ${ }^{1}$, Verônica Bender Haydu²}

\footnotetext{
[1] Universidade Federal da Grande Dourados [2] Universidade Estadual de Londrina I Título abreviado: Interpretação Ambiental pela Análise do Comportamento | Endereço para correspondência: Rua Duque de Caxias, 1235. Jardim Caviuna, Rolândia, PR. CEP 86605-180| Email: veronicahaydu@gmail.com | 10.18761/ PAC.2017.012
} 


\begin{abstract}
This essay discusses the definition, objectives and results of Environmental Interpretation (EI) from an analytical-behavioral view to provide researchers, planners and practitioners of EI, and behavior analysts an alternative of scientific research related to environmental interpretation. For such, the essay presents: (a) some principles and concepts of behavior analysis (BA); (b) the definition of EI in parallel to concepts of BA; (c) the specific objectives of EI based on the principles of BA. BA is the science that studies human behavior through functional analysis in the contexts in which they occur. Parallel to the principles of $\mathrm{BA}$, EI can be understood as an activity that seeks contextual understanding of the individual about the environment, so that the subject constructs meanings that are adequate for conservation of the patrimony it visits. In turn, Environmental Education has broader objectives, not achievable within the spatial and temporal limits of EI. Finally, it is suggested that BA provides principles and methods relevant to the study and execution of EI, and also that EI is a vast and unprecedented field of applied research for behavior analysts to explore.
\end{abstract}

Keywords: Environmental Education; Applied Behavior Analysis; Environmental Awareness; Environment.

Resumen: Este ensayo discurre acerca de la definición, de los objetivos y de los resultados de la Interpretación Ambiental (IA), a partir de una visión analítica-conductual para proporcionar a los investigadores, planificadores y profesionales de la IA, y a los analistas del comportamiento una alternativa de investigación científica relacionada con la IA. Para ello, se presentaron: (a) algunos principios y conceptos del Análisis del Comportamiento (AC); (b) la definición de IA en paralelo a los conceptos de la AC; (c) los objetivos específicos de la IA a la luz de los principios de la AC. La AC es la ciencia que estudia el comportamiento humano por medio del análisis funcional en los contextos en que ocurren. En paralelo a los principios de la AC, la IA puede ser entendida como una actividad que busca entendimiento contextual del individuo sobre el medio ambiente, para que construya significados que sean adecuados para la conservación del patrimonio visitado. Por su vez, la Educación Ambiental tiene objetivos más amplios, no alcanzables en los límites espaciales y temporales de la IA. Por último, se sugiere que la $\mathrm{AC}$ proporciona principios y métodos relevantes para el estudio y la ejecución de la IA, así como que los analistas del comportamiento tienen en la IA un vasto e inédito campo de investigación aplicado a explorar.

Palabras-clave: Educación Ambiental, Análisis del Comportamiento Aplicada, Sensibilización Ambiental, Medio Ambiente. 
Ensinar as pessoas a se comportarem adequadamente nos ecossistemas, ou seja, de maneira que não degradem demasiadamente os recursos naturais, é considerado indispensável para o enfrentamento dos problemas de ordem ambiental, amplamente identificados e pronunciados pelos cientistas nessas últimas décadas. Muitos ambientes representam oportunidade ímpar para tal aprendizado, como são os ambientes naturais ainda intactos e os locais de história ambiental relevante. A pertinência de proteger o que ainda resta de ecossistemas conservados fez das atividades recreativas junto à natureza (trilhas, camping, esportes) de suma importância ao desenvolvimento ecologicamente sustentável. Quando executadas conforme planejamento prévio, tais atividades encaixam-se dentro do que hoje se conhece por Interpretação Ambiental e podem ter valor educativo único no âmbito da Educação Ambiental.

Apesar de relacionados, Interpretação Ambiental e Educação Ambiental são conceitos distintos. A Educação Ambiental pode ser considerada como um movimento político, pedagógico e científico que objetiva o resgate de determinados valores e objetivos educacionais; um movimento que busca a reforma educativa no sentido de valorizar o saber ambiental nos espaços formais, não formais ou informais de educação, e que deve ser uma dimensão ininterrupta na vida dos indivíduos (Loureiro, 2005; 2009). Por outro lado, a Interpretação Ambiental não é um movimento reformista, mas uma atividade recreativa, educativa, pontual e situada, por meio da qual é objetivado que as pessoas vivenciem momentos de lazer que promovam aprendizados acerca de determinados conteúdos em intervalo limitado de tempo e espaço (Ham, 2007a; Ham, 2007b; Vasconcellos, 2006). Quanto às origens, sumariamente, a Educação Ambiental surge a partir das preocupações com as crises e tragédias ambientais e do reconhecimento pela Conferência das Nações Unidas sobre o Meio Ambiente Humano (realizada em 1972) de que mudanças profundas na organização do conhecimento são necessárias à resolução da problemática ambiental (Leff, 2011). A Interpretação Ambiental, por outro lado, tem seu início anterior ao da Educação Ambiental e está intimamente relacionada ao surgimento dos primeiros parques norte-americanos e à recreação de seus visitantes (Vasconcellos, 2006).

A Interpretação Ambiental é uma prática cada vez mais frequente no mundo todo e é estudada e praticada por guias, monitores e planejadores de instituições relacionadas ao turismo ecológico (Vasconcellos, 2006). Seu objeto principal são as visitações em lugares de importância ecoturística, tais como os parques e as Reservas Particulares do Patrimônio Natural (RPPN) abertas à visitação no Brasil. Sua meta é que o público aprenda sobre os lugares visitados com prazer e responsabilidade, de forma que a visita se torne recreativa, educativa e ecologicamente sustentável. Já a Educação Ambiental possui objetivos educacionais mais amplos do que os propostos para a Interpretação Ambiental. Os métodos aplicados para a Educação Ambiental visam alcançar o desenvolvimento de competências e da cidadania ambiental ao longo de toda a vida dos indivíduos. Menos ambiciosa, a Interpretação Ambiental tem como meta a compreensão, a sensibilidade e a responsabilidade do indivíduo para com o patrimônio vivenciado no momento da visitação. A diferenciação teórica e prática entre a Interpretação Ambiental e a Educação Ambiental é algo dificultoso e problemático para leigos e até mesmo para alguns profissionais da Educação e do Ecoturismo. Isso ocorre pelo fato de haver uma relação bastante estreita entre ambas: o alcance da competência ambiental exige que haja compreensão a respeito do meio ambiente, da mesma maneira que só há a cidadania para com aquilo que importa ao indivíduo, ou seja, referente ao que ele é sensível. Por esse ponto de vista, a Interpretação Ambiental pode ser considerada uma atividade relevante ao alcance dos objetivos da Educação Ambiental.

Metodologicamente, na Interpretação Ambiental, os intérpretes ambientais agem de forma a preparar o ambiente a ser visitado no âmbito físico e discursivo, com a meta de torná-lo um evento capaz de garantir a disciplina, a atenção e a reflexão do indivíduo no momento da visitação. Um ambiente fisicamente preparado para a realização da Interpretação Ambiental contém elementos que facilitam o acesso e a contemplação de seus recursos, ao passo que dificultam comportamentos distraídos e degradadores. Já no âmbito discursivo, planeja-se para que o ambiente possua mensagens acessíveis 
aos visitantes. O grau de influência da Interpretação Ambiental, segundo Ham (2007a), depende de como essas mensagens são formuladas e apresentadas à audiência.

Grande e relevante parte do que é atualmente teorizado sobre a Interpretação Ambiental é suportado por teorias da Psicologia Social, principalmente pela Theory of Planned Behavior (Ajzen, 1991), o que pode ser observado em trabalhos como Moscardo, Woods e Saltzer (2004) e Ham (2007a; 2007b). A teoria descrita por Ajzen (1991) estabelece previsão e explicação de comportamentos com base nas crenças que os indivíduos apresentam a respeito dos assuntos relacionados ao comportamento em questão. De acordo com a Theory of Planned Behavior, dois são os principais estímulos que levam os indivíduos a se engajarem em comportamentos: o "controle comportamental percebido" e a "intenção de agir". A percepção do controle que o indivíduo exerce sobre um dado comportamento diz respeito ao conhecimento sobre quão dificultosa é a realização de determinada ação. A intenção de agir é mais complexa e é estimulada por conjuntos variáveis de crenças de acordo com a situação e o comportamento-alvo. Sumariamente, Ajzen (1991) indica como os principais fatores que estimulam a intenção de agir: as crenças a respeito da própria ação, da pressão social que há sobre o comportamento em pauta e da percepção sobre o autocontrole.

Embasado na Theory of Planned Behavior, Ham (2007a) explica que a Interpretação Ambiental pode fazer a diferença no ponto em que os discursos levam a audiência a refletir e, desse modo, fortalecer, modificar ou criar novas crenças a respeito dos temas abordados. As crenças levam às atitudes, que são os sentimentos, intenções e os juízos de valor que as pessoas têm a respeito dos assuntos. Segundo Ajzen (1991), as atitudes do indivíduo em relação aos comportamentos e às normas sociais, junto ao autocontrole percebido, é o que determina, explica e prediz o engajamento nas ações. Ademais, Ajzen (1991) alerta para o fato de que atitudes sobre comportamentos mais gerais não podem determinar comportamentos específicos. Comportamentos específicos estão sob a função de atitudes também específicas e, conforme Ham (2007b), a atitude de apreciação pelos recursos in- terpretados na Interpretação Ambiental pode levar a comportamentos de proteção (conservação ou preservação) desses recursos.

Nos trabalhos sobre Interpretação Ambiental baseados na teoria de Ajzen (1991) - dos quais se destacam os de Cialdini (1996), Ham e Krumpe (1996) e Moscardo, Woods e Saltzer (2004) - os autores utilizam os termos "crença" e "atitude" como sendo distintos a "comportamento". Eles consideram como comportamento apenas os atos de acesso público e estabelecem o aprendizado como um esquema em cadeia, no qual as crenças levam às atitudes que, por sua vez, levam ao comportamento. Uma visão diferente do que é comportamento é apresentada pelos analistas do comportamento, cujos fundamentos se baseiam no Behaviorismo Radical [uma filosofia da ciência fundada por B. F. Skinner (cf., Skinner, 1994)]. De acordo com essa filosofia, as explicações baseadas em relações de causa e efeito devem ser substituídas por explicações baseadas nas relações entre variáveis dependentes e independentes (Chiesa, 1994), fazendo-se análises de contingências ou análises funcionais dos comportamentos. Segundo esses fundamentos, a fala, os pensamentos, as crenças e as atitudes são classes de comportamentos tanto quanto os atos públicos de abrir portas ou de jogar lixo no chão, e devem ser compreendidos como relações comportamentais (Tourinho, 2003). Contudo, aproximações entre essas (diferentes) concepções podem ser feitas.

Significativos avanços no entendimento da funcionalidade e importância da Interpretação Ambiental para a Educação Ambiental foram promovidos a partir de Ajzen (1991), mas essas explicações podem ser complementadas e enriquecidas pelos princípios da Análise do Comportamento, conforme proposto no presente estudo. Isso foi feito com base no argumento apresentado por Skinner (1953/2003) de que, para que possa ser considerada uma ciência natural, não é suficiente explicar o comportamento levando em consideração apenas fatores intrínsecos ao organismo - como são caracterizadas as crenças, os valores, os sentimentos e as intencionalidades - ainda mais quando inacessíveis publicamente (comportamentos encobertos) - como é a reflexão proposta por Ham (2007a), anteriormente citada. O comportamento de um organismo deve ser entendido a partir de suas relações 
com um ambiente (acessível ao investigador) do qual é função.

Para determinar a função dos comportamentos, os analistas do comportamento propõem a realização de análises funcionais, por meio das quais se determinam as variáveis que estabelecem e que mantêm o comportamento. Isso é feito por meio da manipulação de variáveis ambientais e na descrição das relações de contingência entre os eventos antecedentes e as consequências das repostas emitidas (Hanley, Iwata, \& McCord, 2003; Matos 1999). Dessa forma, são descritas as relações de contingência dos comportamentos, permitindo prever o comportamento e determinar como um organismo se comportará em uma situação específica (Skinner, 1953/2003).

Com base nos fundamentos do Behaviorismo Radical, o analista do comportamento é tido como sendo um cientista natural que considera que as mudanças comportamentais são produzidas por processos de seleção pelas consequências (Matos, 1999). Por isso, os princípios da Análise do Comportamento podem ser importantes para o estudo dos métodos e resultados da Interpretação Ambiental, conforme se pretende esclarecer neste artigo. Além desses princípios, a Análise do Comportamento Aplicada, uma subárea da Análise do Comportamento (e. g., Baer, Wolf, \& Risley, 1968; 1987), na qual as intervenções planejadas dos analistas do comportamento se inserem (Carvalho Neto, 2002), deve ser explorada como uma importante fonte de tecnologias e de conhecimento para intervenções nos mais diversos campos de atuação do psicólogo e de profissionais de áreas afins. Isso, porque o foco da Análise do Comportamento Aplicada é estudar comportamentos socialmente relevantes, como é o caso dos padrões comportamentais implicados na Interpretação Ambiental.

As preocupações de analistas do comportamento com questões ambientais remontam, pelo menos, aos anos de 1970 (Dal Ben, Camargo, \& Melo, 2016), podendo-se observar que tecnologias comportamentais e métodos de intervenção foram propostos e avaliados para o desenvolvimento de comportamentos pró-ambientais. Um exemplo dessa preocupação é a edição especial do The Behavior Analyst (Heward \& Chance, 2010), na qual várias propostas de intervenção foram apresentadas para o desafio das mudanças climáticas.
Outro exemplo é o estudo desenvolvido por Leeming Hansen, Alavosius e Reimer (2013), que avaliou a implantação de um programa de sustentabilidade comportamental em uma instituição turística (Embassy Suites Lake Tahoe). O programa visou reduzir o desperdício de bens de consumo, por meio da adoção de reciclagem e compostagem, e a redução do consumo de eletricidade e combustível com práticas de monitoramento, bem como encorajar funcionários e hóspedes a se envolverem em práticas de conservação. $\mathrm{O}$ contexto de um resort oferece um ambiente hospitaleiro, com a oferta de atividades de lazer, entretenimento e de contemplação de seus recursos naturais, o que possibilita fortalecer comportamentos de conservação, como acontece na Interpretação Ambiental. No programa desenvolvido, os hóspedes eram expostos a tecnologias comportamentais durante a sua estadia, que se caracterizava como prazerosa e de entretenimento, dando condições para que houvesse generalização das práticas favoráveis ao desenvolvimento sustentável para situações e contextos cotidianos semelhantes. O mesmo foi esperado da comunidade local, uma vez que a instituição empregava 250 funcionários que residiam em cidades dos arredores. Os resultados do estudo demonstram mudanças comportamentais no nível organizacional e cultural, os quais são potencialmente replicáveis. Leeming et al. concluíram que a indústria do lazer oferece locais particularmente interessantes para mudanças culturais, como as que foram observadas nesse estudo, em que alterar contingências comportamentais para todo o staff da instituição, desde diretores, gerentes e demais funcionários, possibilitou compartilhar seus esforços com os hóspedes e a comunidade local.

Com base nos argumentos apresentados até aqui e, principalmente, devido à importância de se fortalecer comportamentos relevantes para a preservação ambiental, este ensaio buscou apresentar os objetivos específicos da Interpretação Ambiental em relação com a Educação Ambiental e discorrer a respeito da definição, dos objetivos e dos resultados da Interpretação Ambiental a partir de uma visão analítica-comportamental, no intuito de fornecer aos pesquisadores, aos planejadores e aos praticantes da Interpretação Ambiental, perspectivas de estudos e de ações baseadas em análises de contin- 
gências em vigor nos diversos contextos ambientais de suas intervenções. Além disso, este trabalho visou apresentar aos analistas do comportamento uma alternativa de área de pesquisa e de intervenção em um campo que, provavelmente, ainda não tem contribuições baseadas nos princípios da Análise do Comportamento, conforme demonstra busca bibliográfica feita na base de dados Web of Science (para justificar este trabalho) e a revisão de literatura desenvolvida por Haydu (2012). Para atingir os objetivos propostos, as seções apresentadas a seguir abordam sobre: (a) alguns princípios e conceitos da Análise do Comportamento; (b) a definição de Interpretação Ambiental em paralelo a conceitos da Análise do Comportamento; e (c) os objetivos específicos da Interpretação Ambiental à luz dos princípios da Análise do Comportamento. Conclusivamente, são feitas considerações sobre possibilidades de aplicação da Análise do Comportamento à Interpretação Ambiental.

\section{Alguns princípios e conceitos da Análise do Comportamento}

Esta seção apresenta alguns dos princípios e conceitos da Análise do Comportamento que podem auxiliar estudiosos da Interpretação Ambiental a compreendê-los. Além disso, permitir um paralelo entre eles e a definição de Interpretação Ambiental e os termos comumente utilizados por estudiosos da área - o que deve contribuir para um melhor entendimento da seção seguinte a esta.

Para a Análise do Comportamento, uma parte significativa dos comportamentos aprendidos ao longo da vida dos seres humanos é formada por comportamentos denominados operantes, por se caracterizarem como comportamentos que operam mudanças no ambiente (as consequências do comportamento). As consequências, por sua vez, alteram a probabilidade de ocorrerem comportamentos semelhantes aos que as produziram. Dizse que uma consequência tem função reforçadora sobre um comportamento quando se observa um aumento na frequência desse comportamento após sua ocorrência (Skinner, 1953/2003). O princípio do reforço, portanto, é fundamental para uma análise funcional do comportamento.
Para realizar análises desse tipo, deve-se considerar que as consequências das repostas emitidas podem produzir, além do aumento na frequência do comportamento, sua diminuição. Isso ocorre quando o comportamento produz uma consequência aversiva ou a remoção de um reforço presente na situação (Baum, 1994/2006), caracterizando o que é denominado punição. A redução na frequência de determinado comportamento também é observada quando uma determinada resposta que vinha sendo reforçada deixa de ser seguida pela consequência que produzia anteriormente (Catania, 1998/1999), processo denominado extinção.

Uma resposta do organismo que produz determinada consequência na presença de determinado evento ambiental e não de outro, passa a ser controlada por esse evento (Catania, 1998/1999), levando à discriminação de estímulos. Assim, não só as consequências do comportamento fazem parte da relação de contingência que controla sua frequência, mas também os eventos diante dos quais ocorreu o reforço. Esses eventos são designados estímulos discriminativos e o processo observado, controle de estímulos (Skinner, 1953/2003).

Outro conceito importante para o presente estudo é o de comportamento verbal, apresentado por Skinner (1957), que é um comportamento operante, diferindo dos demais por ter outras pessoas como fonte das consequências que o controlam. Um episódio verbal é aquele que conta com a participação de um falante e de uma audiência (ouvinte) capaz de reforçar o comportamento dele (Skinner, 1957). As relações entre a consequência provida pelo ambiente e a ação verbal do indivíduo são reguladas por práticas culturais. "As pessoas que ouvem e reforçam o que uma pessoa diz são membros da comunidade verbal dessa pessoa - o grupo de pessoas que falam entre si e que reforçam as verbalizações umas das outras" (Baum, $1994 / 2006$, p. 137). Baum ainda acrescenta que todo comportamento verbal é comunicativo afinal, há muitos comportamentos operantes reforçados por outras pessoas, mas não chegam a ser comunicativos - mas nem toda comunicação é comportamento verbal - como quando ocorre por meio da liberação de feromônios.

Uma categoria de comportamentos verbais descrita por Skinner (1957) e que tem certa relevância 
neste trabalho sobre Interpretação Ambiental é o tato. Trata-se de um comportamento cujo estímulo discriminativo é a "mudança no campo sensorial [...] do emitente" (Matos, 1991) em decorrência do surgimento de um evento ambiental. A resposta é a fala que estabelece identidade funcional com o objeto percebido pelo emitente, que seja em algum grau correspondente ao objeto discriminado e que essa correspondência seja também compartilhada pela comunidade verbal. A correspondência, nesse caso, não se trata de topografia, mas de funcionalidade. A consequência para o comportamento do emitente, geralmente é a aprovação (um reforço social).

Pesquisas no âmbito da Análise do Comportamento descritas em Beckert (2005) demonstraram que é possível haver correlação entre comportamentos verbais e comportamentos não verbais caso haja um treino de correspondência, um procedimento que estabelece reforços para comportamentos verbais correspondentes a comportamentos não verbais, e vice-versa. Esse é um procedimento que comumente ocorre desde os primeiros anos de vida do indivíduo na maioria das sociedades, na medida em que a comunidade verbal aprova a congruência entre seus comportamentos e pune as contradições. Desse modo, a relação entre as crenças, as atitudes e os atos pró-ambientais de acesso público é reconhecida no campo da Análise do Comportamento, mas não entendida de maneira tão linear e determinística como parece ter sido descrita pelos autores no campo da Interpretação Ambiental, anteriormente citados.

Crenças e atitudes são exemplos de comportamentos verbais dos quais, segundo Guerin (1994), são inferidos comportamentos encobertos. As crenças são consideradas, por esse autor, como sendo afirmações de resultados e as atitudes afirmações de preferências. As atitudes podem ter a função de tatos ao informarem eventos privados. Guerin descreveu que a função de tato das atitudes, provavelmente, é desenvolvida a partir da generalização de tatos de estímulos do ambiente físico externo para estímulos do próprio comportamento. Skinner (1957) descreve que os membros da comunidade podem ensinar o indivíduo a relatar eventos privados na medida em que ele emite comportamentos de forma pública na presença de estímulos privados. As atitudes e as crenças podem ter outras funções, mas a diferença entre elas depende das contingências sociais em vigor, uma vez que ambas são comportamentos verbais sob controle de contingências sociais.

Cabe destacar, ainda, que o comportamento verbal possibilita o estabelecimento do comportamento de formular e de seguir regras (e.g., pedidos, conselhos, ordens). As regras são estímulos verbais que especificam contingências (Skinner, 1969/1989), por meio das quais o falante pode modificar o ambiente por intermédio de outro (aquele que segue a regras). O comportamento do falante (emissor da regra) pode ser reforçado porque ele produz alterações no ambiente que foi especificado na regra. O comportamento do ouvinte (aquele que segue a regra) é reforçado por meio de reforços sociais, como aprovação e agradecimento. Os comportamentos de seguir regras se caracterizam como importantes ao ser humano, pois permitem que sejam adquiridos desempenhos motores complexos ou comportamentos que estão sob o controle de contingências fracas ou remotas, encurtando o processo de aprendizagem (Matos, 2001; Skinner, 1968).

Um aspecto importante a ser destacado no que se refere ao comportamento de seguir regras, é que o ouvinte deve compreender o que o falante diz (Hayes \& Hayes, 1989). Isso implica a explicação da aquisição de significados das palavras, conceito abordado por analistas do comportamento (e.g., de Rose, 1993; Sidman, 2000), a partir do que foi denominado formação de classes de equivalência. Ao estabelecer relações condicionais arbitrárias entre eventos (que não possuem propriedades físicas comuns), o que é feito, por exemplo, por meio do procedimento de escolha de acordo com modelo, é possibilitada a emergência de relações condicionais que não foram diretamente ensinadas. As classes de equivalência são formadas por relações condicionais arbitrárias com pelo menos um elemento em comum e pelas relações emergentes que são observadas nesse processo (de Rose, 1993; Sidman, 2000). Se forem considerados como pertencentes a uma classe de equivalência, estímulos como um objeto, a palavra impressa e a falada que a comunidade verbal emprega para designar esse objeto, pode-se haver leitura com compreensão e demonstração da aquisição do significado da palavra (o leitor interessado em se aprofundar nesse tema pode acessar de Rose, Gil, \& Souza, 2014). 
Ainda em reação ao seguimento de regras, deve-se considerar que as regras podem ser estabelecidas pelo próprio indivíduo, o que possibilita o autocontrole. $\mathrm{O}$ autocontrole se caracteriza como sendo um comportamento que envolve repostas que controlam o comportamento do indivíduo e que é desenvolvido quando uma resposta produz, ao mesmo tempo, reforço positivo e negativo ou reforço positivo e punição, ou duas ou mais consequências com diferentes valores reforçadores (Skinner, 1953/2003), ou seja, quando há conflito de contingências. $\mathrm{O}$ autocontrole envolve uma resposta controlada, as contingências que estabelecem propriedades aversivas a essa resposta, e um comportamento controlador que altera a probabilidade de a reposta controlada ocorrer (Hanna \& Todorov, 2002). Esse tipo de processo comportamental é particularmente relevante para a análise de contingências presentes em situações nas quais o responder impulsivo sob controle de consequências imediatas tem uma probabilidade maior de ocorrer do que as respostas que produzem consequências atrasadas.

A aquisição de comportamentos sem a necessidade de uma longa história de aprendizado também pode ocorrer por meio de outro tipo de processo comportamental - a imitação. O comportamento do indivíduo é reforçado à medida que se aproximam topograficamente do comportamento do modelo, membro da comunidade verbal (Skinner, 1953/2003). Esse processo está presente desde muito cedo na vida do ser humano e se mantém ao longo de seu desenvolvimento, contribuindo para a adaptação do indivíduo à cultura vigente. Comportamentos que, por suas consequências não arbitrárias, poderiam demorar demasiada quantidade de tempo para serem aprendidos, são adquiridos já nos primeiros anos de vida devido a contingências arranjadas pelo sistema educacional (conforme especificado anteriormente). Além disso, esse sistema contribui para que comportamentos que poderiam nunca ser aprendidos, e outros que apresentem consequências não arbitrárias tão impactantes ao organismo, sejam aprendidos por instruções e regras.

Conforme os princípios da Análise do Comportamento resumidos aqui, os processos de aprendizagem acontecem na relação de contingência entre a resposta do organismo e os eventos ambientais (contexto e consequência), tanto no nível aberto quanto no encoberto, incluindo resposta verbais e não verbais. O repertório comportamental resultante dessa relação é um fator central na prática e no planejamento da Interpretação Ambiental, e o estudo desses princípios permite a compreensão dos conceitos implicados na definição da Interpretação Ambiental. Um conjunto de conceitos, não menos importante, que descreve processos culturais do ponto de vista da Análise do Comportamento é: linhagem comportamental, linhagem culturo-comportamental e linhagem cultural (Glenn et al., 2016). Esses conceitos são relevantes para a Interpretação Ambiental, uma vez que se trata de uma prática cultural, que relacionada "padrões semelhantes de conteúdo comportamental, geralmente, resultantes de semelhanças em ambientes" (Glenn, 2004, p.140). Entretanto, esses conceitos não serão abordados no presente artigo, pois serão focalizados, nas seções subsequentes, processos de aprendizagem do indivíduo.

\section{A definição de Interpretação Ambiental em paralelo com conceitos da Análise do Comportamento}

O propósito desta seção é discutir a definição de Interpretação Ambiental formulada por Silva (2012). A seguir, encontra-se a definição a ser discutida, sendo que as partes destacadas em negrito serão os principais objetos de análise, pois apresentam termos e conceitos importantes à visão analítico-comportamental do tema.

[A Interpretação Ambiental é] uma arte de explicar e atividade dialógica e recreativa, com o objetivo de construir significados de determinado lugar junto aos seus visitantes, especialmente àqueles casuais. Mas ela não se limita a dar informações, o diálogo deve ser verdadeiro e as explicações devem ocorrer de uma forma breve, emocionante, provocativa e agradável, pela fala ou por meios ilustrativos, na presença do objeto em questão e com experiências de primeira mão. O resultado da Interpretação é a conexão do público com as ideias que lhes são 
apresentadas para uma sensibilização sobre as questões ambientais que tem a função singular de resultar no desejo de conservar o patrimônio que lhe foi apresentado. (Silva, 2012, p. 43; grifo dos autores)

Primeiramente, em relação ao trecho "construir significados [...] junto aos seus visitantes", pode-se propor que os significados são construídos na medida em que os indivíduos aprendem a se comportar de determinadas maneiras na presença de elementos do ambiente, os estímulos discriminativos. Dessa maneira, costuma-se afirmar que as pessoas dão significados às coisas uma vez que se comportam de maneiras específicas frente a elas. É possível afirmar que uma árvore significa "fonte de renda" ao lenhador, pois na presença de muitas árvores seu comportamento é o de extraí-las para a venda da madeira. Contudo, o significado "fonte de renda" não existe por si só e precisou ser construído ao passo que as consequências de ações semelhantes foram reforçadas no passado (o indivíduo adquiriu recursos financeiros), o que vai ao encontro do que foi proposto por Baum (1994/2006): o significado está naquilo que o ato produz como consequência. Ademais, um lenhador não derruba toda e qualquer árvore que vê, ele se comporta de muitas outras maneiras frente a árvores, como quando utiliza suas sombras para descansar, instala um balanço para os filhos brincarem, coleta frutas, admira uma bela espécie etc. Destaca-se, assim, a noção de que o significado não é único, mas plural e é construído na interação do indivíduo com o ambiente e a partir de um entendimento particular do contexto (Catania, 1998/1999). O organismo que se comporta é capaz de perceber as particularidades de cada situação e, assim, escolher as maneiras de agir mais prováveis de serem reforçadas ou de gerarem reforçadores de maior magnitude.

Construir significados pode ser simplesmente tornar um elemento, antes sem função específica, em um relevante estímulo discriminativo, o que em outras palavras pode designar que um elemento de baixa importância ao indivíduo se torne mais significativo (ganhe importância/adquira uma determinada função). No entanto, conforme a definição formulada por Silva (2012), a Interpretação Ambiental não objetiva a construção de significa- dos indeterminados. Não se quer, por exemplo, que o indivíduo veja a floresta simples e unicamente como fonte de renda a ser explorada, mas como um recurso natural importante a ser conservado. Para tal, as estratégias educativas adotadas são no sentido de que a audiência possa entender o contexto mais amplo no qual os assuntos se inserem, possibilitando, assim, que se conheçam, para além das consequências imediatas, as consequências mais distantes (temporalmente e espacialmente) da interação do ser humano com seu ambiente, para que seja desenvolvido o autocontrole. Assim, sobre a floresta, é importante que as pessoas entendam seu significado como "fonte de renda", mas também, como "mantenedora da qualidade da vida humana quando preservada", como "ambiente rico para o lazer", "fornecedor de serviços ambientais indispensáveis", "habitat insubstituível de inúmeras espécies", dentre outros entendimentos importantes à sua utilização de forma ecologicamente sustentável.

O termo "construir" se apresenta no contexto educacional como reação e alternativa aos termos "transmitir", "fornecer", "revelar", dentre outros que são conservadores e remetem à ideia de o aprendiz como um saco vazio a ser preenchido ou um ser desapropriado de conhecimentos, os quais devem lhe ser revelados (Freire, 1968/2005). Conforme explica Guerin (1992), o conhecimento é socialmente construído e se trata de comportamento que foi reforçado pela comunidade verbal. Isso quer dizer que o conhecimento não pode ser transmitido a um indivíduo receptor, mas sim construído socialmente por meio da interação das ações do indivíduo com as ações de outras pessoas.

Outra forma de conhecimento socialmente construído se refere aos comportamentos governados por regras (Guerin, 1992). Ao problema de resistência às consequências diretas do comportamento, citado na seção anterior, acrescenta-se o fato de que as pessoas tendem a seguir regras que lhes são apresentadas por meio da utilização de técnicas de persuasão, o que gera diversos problemas sociais relacionados à alienação. Pode-se dizer que essa relação entre os indivíduos persuasivos e os persuadidos caracteriza um episódio opressivo de interação, no qual o tom autoritário, a fala incessante e o uso de punições são estratégias comumente utilizadas para que os indivíduos sigam regras formais que não, necessariamen- 
te, são adequadas aos contextos em que vivem (alienação). Assim, torna-se importante que "construir significados junto a alguém" seja entendido como arranjar contingências para o aprendizado por meio de comportamento verbal não opressivo.

O ensino pode ser caracterizado como não opressivo quando, além de possibilitar a permuta de papéis entre falante e ouvinte, o falante não persuade a audiência a comportamentos por meio de regras rígidas ${ }^{1}$ e punições, e sim, age no sentido de possibilitar maior autonomia dos indivíduos em responder adequadamente aos estímulos do ambiente. Por exemplo, no caso de o intérprete ambiental dizer à audiência que "o agricultor não deve desmatar as matas ciliares para fazer pastos", é importante que o intérprete não discurse sozinho, mas que motive a audiência a pensar e se pronunciar a respeito do assunto abordado, além de reforçar os comportamentos verbais que julgar adequados à situação, tais como aqueles considerados lógicos, que estiverem de acordo com as asserções proferidas ou que se expressem na forma de dúvidas cabíveis.

Uma vez que o uso de regras rígidas e punições para a construção de significados não condiz com a Interpretação Ambiental nos moldes aqui considerados adequados, importa que parte da função do intérprete ambiental seja a de aplicar, possibilitar ou, por vezes, programar reforçadores contingentes aos comportamentos adequados da audiência (atenção, participação, cuidado, disciplina e descrições apropriadas do ambiente). Tais reforçadores podem ser arbitrários ou não arbitrários. Quando arbitrários, não são consequências diretas/ específicas do comportamento, mas sim aplicadas por alguém interessado na manutenção do mesmo. Comumente eles são liberados pelo intérprete ambiental ao pronunciar mensagens de aprovação à audiência ou por meio de, por exemplo, sorrisos. O ser humano tende a ser sensível a esse tipo de reforçadores (Baum, 1994/2006). Quando não arbitrários, representam as consequências intrínsecas ao comportamento - o efeito da resposta emitida sobre o ambiente.

1 O sentido de "rígidas" é o de que não podem ser negociadas. No caso abordado pelo texto, as decisões ocorrem unilateralmente, de modo que resta à audiência apenas obediência.
Para que as consequências não arbitrárias sejam reforçadoras (ou punitivas) é preciso que o indivíduo entre em contato com elas, de forma que estabeleça relação com a resposta que as gerou. Se, por exemplo, o lixo que é jogado na rua causa a poluição dos rios da região, mas o poluidor não toma conhecimento do fato, a consequência não exercerá controle sobre seu comportamento. Por outro lado, se ocorre uma enchente e o lixo vai parar, novamente, dentro da residência do poluidor, seu comportamento poderá ser afetado por essa consequência. É função do intérprete ambiental falar sobre as relações entre o comportamento humano e suas consequências e criar possibilidades para que a audiência entre em contato com tais consequências, levando-a a observar impactos no ambiente (sejam positivos ou negativos) produzidos pelas ações humanas.

Uma das maneiras pelas quais os indivíduos aprendem a respeito do assunto abordado pelo intérprete ambiental é imitando seu comportamento verbal. Ao imitar o comportamento verbal do intérprete ambiental, o indivíduo pode fazê-lo de forma aberta (falando com outros indivíduos) ou encoberta (pensando de forma privada a respeito). No entanto, para que o repertório comportamental aprendido se mantenha, é preciso que as respostas emitidas sejam reforçadas. É nesse sentido que a Interpretação Ambiental apresenta alguma vantagem sobre o ensino formal, pois na escola a maioria dos comportamentos para a qual se consegue programar reforços necessita acontecer de forma aberta e, para isso, são aplicados métodos avaliativos que têm a função de estimular as verbalizações aprendidas pelo aluno. Por outro lado, em situações de Interpretação Ambiental é possível o contato direto com os objetos e situações que se equivalem ao comportamento verbal aprendido, e presenciá-los de forma que se possa verificar a correspondência do comportamento verbal (emitido na forma pública ou privada) com a realidade (recursos do local visitado) é algo reforçador (Skinner, 1968; 1953/2003). Apresentar comportamento verbal vocal frente a situações não verbais equivalentes é uma forma de "controlar o mundo físico com sucesso", o que, de acordo com Skinner (1953/2003, p. 86), é automaticamente reforçador. Se, por exemplo, o intérprete ambiental tem como 
objetivo que o visitante de um parque saiba sobre a função dos pássaros na dispersão das sementes, podem ser feitas práticas de observação de pássaros se alimentando de frutos, de fezes dos pássaros com sementes, das mudas jovens em brotamento longe das plantas-mãe etc. Situações que, de alguma forma, possam se tornar estímulos para o comportamento do visitante e que, com a ajuda das explicações do intérprete, servir de argumento para a tese apresentada.

Em eventos em que os elementos importantes para a experiência do aprendiz não são de fácil observação em campo, as contingências podem ser programadas artificialmente, como para a observação da importância da cobertura vegetal na infiltração e escoamento da água das chuvas no solo. Nesse caso, faz-se o uso de maquetes ou outros recursos que apenas simulem os acontecimentos naturais. Pode-se afirmar, ainda, que a atividade do intérprete ambiental é importante no que se refere à facilitação da observação, por parte da audiência, de situações inéditas ("experiências de primeira mão") e que, portanto, seriam de difícil entendimento e significação. A respeito dessa última importância, Baum (1994/2006, p. 66) explica que "os atos sensoriais são modificados pela experiência”. De acordo com esse autor, as experiências com situações inéditas junto a estimulações verbais de outrem ("ouça isso"; "olhe para aquilo") podem levar ao "ver discriminativo", de modo que o entendimento da situação se torna facilitado em experiências semelhantes futuras.

Com base no que foi discutido até aqui, a sentença "construir significados [...] junto aos seus visitantes" pode ser entendida como: facilitar, por meio de comportamento verbal não opressivo, o contato dos visitantes com as consequências importantes ao aprendizado pretendido (consequências reforçadoras). Além disso, o conceito de classes de equivalência (Sidman, 2000) também se aplica, uma vez que, ao serem estabelecidas relações arbitrárias entre eventos relacionados ao fenômeno natural, como a descrição de um evento da natureza, a maquete que simula esse evento e o próprio fenômeno natural (por exemplo, o caminho da água em um escoamento da chuva no solo), possibilita que relações de equivalência sejam formadas e o significado do fenômeno, compreendido.
Em relação à última frase da definição de Interpretação Ambiental em discussão, três termos merecem atenção especial: "conexão do público", "sensibilização" e "resultar no desejo". Compreende-se o termo "conexão" como "compreensão e formação de crenças". Por sua vez, o "desejo de conservar" é uma atitude do indivíduo, algo que ele declara (abertamente ou para si mesmo) sentir e valorizar. Dessa maneira, a última frase da definição de Interpretação Ambiental apresentada pode ser entendida da seguinte maneira: o resultado da Interpretação Ambiental é o desenvolvimento de regras (ou autoregras) do público em relação às contingências que lhes são apresentadas. Regras que venham a controlar comportamentos que possam ser caracterizados como mudança das atitudes (referentes às questões ambientais), as quais têm a função singular de aumentar a probabilidade de conservar o patrimônio que lhe foi apresentado.

Pela definição de Interpretação Ambiental apresentada e pelo que foi discutido até aqui, infere-se que o objetivo maior da Interpretação Ambiental é possibilitar que o público apresente comportamentos de entendimento contextual do ambiente, para que construa significados (aprenda a responder de maneiras específicas a determinados estímulos e formule regras/autoregras) que sejam adequados à conservação do patrimônio visitado. Contudo, para melhor compreensão desse tema, é necessário que se discuta mais especificamente a respeito desses comportamentos de entendimento, assim como suas funções para o contexto mais amplo no qual se insere a Interpretação Ambiental: a Educação Ambiental.

\section{Os objetivos específicos da Interpretação Ambiental à luz dos princípios da Análise do Comportamento}

É possível observar que, muitas vezes, atividades simples de Interpretação Ambiental, como trilhas ecológicas em parques, são consideradas como sendo a própria Educação Ambiental em ação. No entanto, apesar de abordar sobre temas semelhantes, a Interpretação Ambiental e a Educação 
Ambiental, como já apresentado anteriormente, são propostas e áreas do conhecimento distintas tanto em relação às suas origens quanto à amplitude de suas ações e objetivos. No mais, essa diferença vem diminuindo ao passo que ambas vêm sendo correlacionadas em diversas propostas educacionais e o principal fator que contribui para isso é a coincidência existente em seus objetivos específicos (Pedrini, 2007). Os três principais conjuntos comportamentais que fazem parte do entendimento contextual do indivíduo a respeito do meio ambiente (resultado esperado da Interpretação Ambiental) são a sensibilidade, a compreensão, e a responsabilidade (Ham, 2007a; Ham 2007b). Esses também são repertórios comportamentais objetivados para a Educação Ambiental, como é possível verificar em Smyth (2006), ao listar os resultados visados pela Educação Ambiental como: sensibilidade ambiental (environmental awareness); compreensão ambiental (environmental literacy); responsabilidade ambiental (environmental responsibility); competência ambiental (environmental competence); e cidadania ambiental (environmental citizenship). Isso explica a relação que normalmente é estabelecida entre a Educação Ambiental e a Interpretação Ambiental, no entanto, pode-se dizer que a Educação Ambiental possui objetivos mais ambiciosos que a Interpretação Ambiental que, por contar com intervalo limitado de tempo e espaço para sua realização, concentra esforços no alcance apenas dos três primeiros resultados listados por Smyth (2006).

A sensibilização ambiental do indivíduo poderia ser dita um processo de mudança de atitudes sobre os temas ambientais. Em relação ao desmatamento, por exemplo, o indivíduo, antes indiferente, pode demonstrar desprezo após sensibilizado. No entanto, dificilmente há sentimentos e juízos de valor acerca de assuntos que o indivíduo não compreende - o que é diferente de compreender erroneamente. Compreensões errôneas, por sua vez, podem levar a atitudes inadequadas. Por esse motivo, dentre outros, a compreensão ambiental é um resultado importante de ser alcançado. Pode-se dizer que compreender implica em formar crenças - no sentido exposto por Ajzen (1991). Desse modo, os comportamentos relativos à compreensão do indivíduo, acerca de algo, são verbais. No entanto, diferentemente da sensibi- lidade, na qual esse "algo" representa o autoconhecimento do indivíduo sobre o que ele sente, o que pretende e os juízos de valor que faz das coisas, o "algo" da compreensão ambiental é sobre os componentes do ambiente e suas relações.

É importante frisar que, de acordo com Baum (1994/2006), é muito utilizado o argumento de que apenas o próprio indivíduo, por meio da introspecção (um olhar para o que há dentro de si), é capaz de desenvolver seu autoconhecimento. Entretanto, isso só é possível no caso de a comunidade verbal ensinar o indivíduo a produzir esse tipo de conhecimento. Como já discutido anteriormente e conforme Baum afirmou, o autoconhecimento sobre atitudes frequentemente depende do reconhecimento de estímulos que envolvem mais eventos públicos do que privados. Isso possibilita que, por imitação, o indivíduo se comporte de maneira semelhante e, ao fazê-lo, que seu comportamento seja reforçado. Essa forma de interpretar os fenômenos comportamentais permite estabelecer que o tato de eventos privados (comportamento verbal encoberto) possa ser ensinado. Além disso, deve-se considerar que respostas verbais encobertas na forma de tato, como foi destacado por Gongora (2003, p. 77), têm função de "esclarecer rapidamente uma situação", contribuindo para que o indivíduo identifique com rapidez aspectos relevantes de situações novas ou complexas, aumentando assim a probabilidade de outros comportamentos apropriados para a situação e do reforço desses comportamentos. O discurso do intérprete ambiental, por exemplo, pode ser composto por muitas mensagens ditas normativas, que descrevem sentimentos, pretensões e valores sociais referentes às situações e objetos interpretados e pela emissão de tatos que esclarecem funções de eventos contextuais da interpretação ambiental (Silva, 2012). As mensagens apresentadas pelo intérprete ambiental podem servir de estímulo para que o indivíduo da audiência se comporte de maneira semelhante (imitação) e, possivelmente, tenha seus sentimentos e juízos de valor colocados em relações de contingências arranjadas pelo educador e pela comunidade. Os tatos por sua vez, podem esclarecer variáveis presentes no contexto da interpretação ambiental e aumentar a probabilidade de o indivíduo emitir tatos encobertos em situações semelhantes, comportamentos adequados às situa- 
ções presentes nesse ambiente, bem como de haver generalização para contextos equivalentes.

A responsabilização ambiental descrita por Smyth (2006) pode ser caracterizada como sendo um processo de ensino do comportamento verbal, cujo aprendizado deve girar em torno da função do aprendiz no ambiente e dos impactos produzidos pelas suas ações. Para Sato (2002), a responsabilização ambiental se caracteriza pelo reconhecimento, por parte do educando, de que o ser humano é um protagonista na manutenção do mundo em que vive. Assim, responsabilização ambiental é o processo educacional que leva o indivíduo a reconhecer sua função como modificador do ambiente e, portanto, suas responsabilidades como tal. Os comportamentos relativos à responsabilidade ambiental envolvem tanto comportamentos de compreensão ambiental (verbalizações sobre a ecologia do ser humano na natureza) quanto de sensibilidade ambiental (verbalizações sobre a relevância de ações ecologicamente sustentáveis). Argumenta-se aqui que ter a responsabilização ambiental como um objetivo a parte deva ser importante pelo fato de a responsabilidade - para além da compreensão e de atitudes a respeito de aspectos não humanos da natureza - servir de estímulo especialmente importante ao desenvolvimento da cidadania ambiental.

A cidadania ambiental é o objetivo último da Educação Ambiental, é o que se quer, definitivamente, alcançar nos educandos. Exercer a cidadania ambiental consiste da apresentação, frente a estímulos próprios do ambiente, de comportamentos (verbais ou não verbais) realmente efetivos na solução ou na "não geração" de problemas de ordem ambiental (socialmente definidos). Para Smyth (2006), cidadania implica em uma concepção de participação como um membro efetivo do ambiente como um todo e em suas nuances: na família, na comunidade, na sociedade, no ecossistema, na biosfera etc. Atos de cidadania ambiental podem ser exemplificados por: instruir adequadamente um vizinho sobre como lavar a calçada (comportamento verbal adequado) ao se observar o uso indevido da mangueira (estímulo do ambiente); separar e destinar os resíduos sólidos de acordo com suas tipologias (comportamentos não verbais adequados) quando isso não é feito pela instituição de destino (estímulo do ambiente); evitar o consu- mo exagerado de utensílios descartáveis (comportamento adequado) frente à ineficiência do sistema social no tratamento dos resíduos (estímulo do ambiente); dentre outros.

Para que os comportamentos ambientalmente cidadãos ocorram, não basta somente o saber sobre ser um cidadão, é necessário que o indivíduo aprenda comportamentos procedimentais (saber fazer) importantes às etapas de seu agir cidadão e que compõem um repertório que é classificado por Smyth (2006) como sendo a competência ambiental. Para que esse aprendizado ocorra, é necessário que conteúdos específicos componham a prática educativa e que os educandos sejam submetidos a situações que estimulem a emissão de comportamentos procedimentais. Alguns desses comportamentos são costumeiramente reforçados em atividades de Interpretação Ambiental, como é a observação, a reflexão, o cuidado com os elementos do ambiente e, por vezes, o debate. Porém, são reconhecidos os limites temporais e espaciais da Interpretação Ambiental, o que frequentemente leva os educadores ao não planejamento de situações especificamente voltadas ao aprendizado de competências ambientais.

Se comportar com entendimento contextual no ambiente, de maneira adequada e não prejudicial, no caso da Interpretação Ambiental, significa, portanto, apresentar um repertório de comportamentos verbais a respeito dos componentes do ambiente (incluindo o ser humano e, consequentemente, o próprio ator do comportamento), de suas relações e dos juízos de valor que os envolvem e, também, de comportamentos não verbais associados à sustentabilidade das ações nas quais o indivíduo se engaja na visitação aos locais onde a atividade de Interpretação Ambiental ocorre. Assim, a Interpretação Ambiental se estabelece como parte importante de programas mais amplos de Educação Ambiental, uma vez que, tendo seus objetivos alcançados, ensina aos indivíduos comportamentos relevantes ao desenvolvimento da cidadania ambiental. 


\section{Considerações finais}

Interpretação Ambiental não é Educação Ambiental, a consideração contrária gera o risco de um problema comumente observado em diversas propostas educacionais: a realização de atividades simplistas e pontuais sob o emblema da Educação Ambiental, mas que não geram os resultados pretendidos/esperados. O que se pode afirmar é que, atualmente, a Interpretação Ambiental pode ser considerada uma atividade de Educação Ambiental, pois comumente é usada para auxiliar o alcance de seus objetivos. Sob a ótica da Análise do Comportamento, pode-se afirmar que a Interpretação Ambiental se configura como uma atividade de grande importância à Educação Ambiental, uma vez que possibilita que o aprendizado ocorra por meio de ações educativas que buscam: a construção coletiva do conhecimento, trabalhar com o mínimo de punições e possibilitar o contato da audiência com consequências reforçadoras que contribuem para a manutenção dos comportamentos aprendidos. Característica especial da Interpretação Ambiental é a possibilidade de se trabalhar com os reforçadores não arbitrários que se encontram acessíveis nos lugares onde se realiza a atividade - algo menos provável em situações mais formais e em ambientes indoor de educação. Fala-se da árvore frente a ela, conta-se sobre o pássaro observando-o, denuncia-se os abusos presenciando-os, emite-se comportamento de preservação dos recursos naturais in loco e assim por diante.

As discussões realizadas neste trabalho não ocorrem na pretensão de descaracterizar ou substituir as teorias já formuladas e disseminadas sobre a Interpretação Ambiental, mas, sim, de avançar a partir de uma perspectiva analítico-comportamental, abrindo possibilidades tanto para que os pesquisadores e os educadores ambientais entendam as possibilidades de aplicação da Análise do Comportamento à Interpretação Ambiental, quanto para que os analistas do comportamento abordem a respeito do tema sem que haja necessidade de substituição dos termos comumente utilizados ou reformulação total das teorias já descritas. Termos como "crença" e "atitude", por exemplo, não necessitam perder suas funções para a pesquisa e a aplicação da Interpretação Ambiental, pois há a possibilidade de que sejam entendidos como comportamentos (em grande parte, verbais).

Ao se levar em consideração a que se propõe a Interpretação Ambiental e a partir do entendimento de seus objetivos e da relação desses com o contexto mais amplo de crises ambientais e de Educação Ambiental, potencializam-se as possibilidades de que se pesquise e se defina melhor os comportamentos da audiência importantes de serem reforçados, assim como os tipos de reforçadores e as estratégias a serem utilizadas para o alcance dos objetivos propostos. Comportamentos específicos envolvidos com a disciplina, a atenção e a reflexão dos participantes em situações de Interpretação Ambiental, assim como a programação de contingências para que reforçadores possam ser disponibilizados, contribuindo na manutenção e no aumento de frequência desses comportamentos, parecem configurar oportunidade rica de pesquisa e de atuação na área da Educação Ambiental.

Um aspecto que parece merecer atenção é o esclarecimento das diferenças do aprendizado escolar para com o aprendizado em situações de Interpretação Ambiental. Pesquisas com esse foco contribuiriam para o entendimento da importância de investimentos em programas de turismo ecológico, no sentido de promover uma formação mais integral do cidadão pró-ambiental. Análises funcionais das contingências presentes nos contextos de ensino podem revelar comportamentos importantes que são mais bem aprendidos em situações de Interpretação Ambiental do que em situações escolares. A compreensão da função da Interpretação Ambiental para o aprendizado escolar é algo relevante, uma vez que se considera que a atividade interpretativa provavelmente exerça função motivacional para o aprendizado mais formal. Com base nisso, seria possível realizar estudos experimentais com turmas de alunos que venham a participar de atividades de Interpretação Ambiental em fases introdutórias, intermediárias e conclusivas da apresentação dos conteúdos escolares, comparando-as com grupos controle (que não saem a campo e aprendem exclusivamente pelos recursos de sala de aula), ou desenvolvendo estudos com delineamentos de sujeito único, por exemplo, comparando o desempenho de estudantes em ava- 
liações sobre conteúdos escolares relacionados à Educação Ambiental ou investigando a emissão de comportamentos adequados a ecossistemas antes e depois de terem participado de uma atividade de Interpretação Ambiental.

Quanto ao conteúdo discursivo da Interpretação Ambiental, pesquisas aplicadas podem demonstrar a função do que é dito à audiência, dos tipos de mensagens emitidas pelo educador, para o controle de comportamentos envolvidos com a disciplina, a atenção e a reflexão dos indivíduos em momentos de visitação ecoturística. Infere-se, por exemplo, que mensagens imperativas elevem o grau de formalidade da Interpretação Ambiental, fator que pode se tornar negativo à atividade, sendo ela de caráter recreativo (Projeto Doces Matas, 2002). Adotando os princípios da Análise do Comportamento, é possível fazer estudos com diferentes perfis de discurso adotados pelo guia, para que se possa definir um nível ótimo de utilização dos diferentes tipos de mensagens.

Muitas pesquisas embasadas em outros referenciais, que não os da Análise do Comportamento, já tiveram seus focos voltados à pesquisa pura e aplicada na área da Interpretação Ambiental. Entretanto, o método de análise funcional do comportamento adotado como recurso de investigação pelos analistas do comportamento pode revelar aspectos importantes ainda não identificados por outras metodologias. Até onde se encontra o estado da arte, a Análise do Comportamento tem pouca influência no que se refere a essa atividade que se faz tão importante à humanidade no contexto atual de crises ambientais.

\section{Referências}

Ajzen, I. (1991). The Theory of Planned Behavior. Organizational Behavior and Human Decision Processes, 50, 179-211, 1991. doi: 10.1016/07495978(91)90020-T

Baer, D. M., Wolf, M. M., \& Risley, T. R. (1968). Some current dimensions of Applied Behavior Analysis. Journal of Applied Behavior Analysis, 1, 91-97. doi: 10.1901/jaba.1968.1-91

Baer, D. M., Wolf, M. M., \& Risley, T. R. (1987). Some still-current dimensions of applied behavior analysis. Journal of Applied Behavior Analysis, 20, 313-327. doi: 10.1901/ jaba.1987.20-313

Baum, W. M. (2006). Compreender o behaviorismo: Comportamento, cultura e evolução (M. T. A. Silva et al., Trads.). Porto Alegre: Artmed. (Trabalho original publicado em 1994).

Beckert, M. E. (2005). Correspondência verbal/ não-verbal: Pesquisa básica e aplicação na clínica. Em J. Abreu-Rodrigues, \& M. R. Ribeiro (Orgs.), Análise do comportamento: pesquisa, teoria e aplicação (pp. 229-244). Porto Alegre: Artmed.

Dal Ben, R., Camargo, J. C., Figueira, G., \& Melo, C. M. (2017). Análise do comportamento e sustentabilidade: Revisão dos artigos publicados no Behavior and Social Issues de 2005 a 2016. Revista Brasileira de Análise do Comportamento, 12, 86-94. doi: 10.18542/rebac.v12i2.4401

Carvalho Neto, M. B. de (2002). Análise do comportamento: Behaviorismo radical, análise experimental do comportamento e análise aplicada do comportamento. Interação em Psicologia, 6, 13-18. doi: 10.5380/psi.v6i1.3188

Catania, A. C. (1999). Aprendizagem: Comportamento, linguagem e cognição. (D. das G. de Souza et al., Trads.). Porto Alegre: Artes Médicas Sul. (Trabalho original publicado em 1998).

Chiesa, M. (1994). Radical behaviorism: The philosophy and the science. Boston: Autors Cooperative.

Cialdini, R. B. (1996). Activating and aligning two kinds of norms in persuasive communications. Journal of Interpretation Research, 1, 3-10. doi: 10.1080/15534510500181459 
de Rose, J. C. (1993). Classes de estimulos: Implicações para uma analise comportamental da cognição. Psicologia: Teoria e Pesquisa, 9, 283-303.

de Rose, J. C., Gil, M. S. C. A., \& Souza, D. G. (2014). Comportamento Simbólico: Bases conceituais e empíricas. 1. ed. Marilia: Cultura Acadêmica.

Freire, P. A. (2005). Pedagogia do Oprimido (43. Ed.). Rio de Janeiro: Paz e Terra. (Trabalho original publicado em 1968).

Glenn, S. S. (2004). Individual behavior, culture, and social change. The Behavior Analyst, 27, 133-151. Recuperado de: https://www.ncbi. nlm.nih.gov/pmc/articles/PMC2755396/

Glenn, S. S., et al. (2016). Toward consistent terminology in a behaviorist approach to cultural analysis. Behavior and Social Issues, 25, 11-27. doi: 10.5210/bsi.v25i0.6634

Gongora, M. A. N. (2003). Itinerário para analisar comportamento verbal encoberto. In M. Z. Brandão et al. (Orgs.). Comportamento e cognição: A história e os avanços, a seleção por consequências em ação. (vol. 11, pp. 66-81). Santo André, SP: ESETec.

Guerin, B. (1992). Behavior analysis and the social construction of knowledge. American Psychologist, 47, 1423-1432. doi: 10.1037/0003066X.47.11.1423

Guerin, B. (1994). Attitudes and beliefs as verbal behavior. The Behavior Analyst, 17, 155-163. Recuperado de: http://pubmedcentralcanada.ca/pmcc/articles/PMC2733686/pdf/behavan00023-0157.pdf

Ham, H. S., \& Krumpe, E. E. (1996). Identifying audiences and messages for nonformal environmental education - A theoretical framework for interpreters. Journal of Interpretation Research, 1, 11-23. Recuperado de https://eric. ed.gov/?id=EJ541833

Ham, S. (2007a). Can interpretation really make a difference? Answers to four questions from cognitive and behavioral psychology. Proceedings of II Interpreting World Heritage Conference, Vancouver, Canada, 42-52.

Ham, S. (2007b). From interpretation to protection: Is there a theoretical basis? Journal of Interpretation, 14, 49-57. Recuperado de: https://www.interpnet.com/docs/JIR-v14n2.pdf
Hanley, G. P., Iwata, B. A., \& McCord, B. E. (2003). Functional analysis of problem behavior: A review. Journal of Applied Behavior Analysis, 36, 147-185. doi: 10.1901/jaba.2003.36-147

Hanna, E. S., \& Todorov, J. C. (2002). Modelos de autocontrole na análise experimental do comportamento: Utilidade e crítica. Psicologia: Teoria e Pesquisa, 18, 337-343. doi 10.1590/ S0102-37722002000300014

Haydu, V. B. (2012). Analise aplicada do comportamento: O que é, como fazer e o que tem sido pesquisado. Em V. B. Haydu, \& S. R. de Souza, (Orgs.), Psicologia comportamental aplicada: Avaliação e intervenção nas áreas da saúde, da clínica, da educação e do esporte (pp. 13-51). Londrina: EDUEL.

Hayes, S. C., \& Hayes, L. J. (1989). The verbal action of the listener as a basis for rule-governance. Em S. C. Hayes (Org.), Rule-Governed behavior: Cognition, contingencies, and instructional control (pp.153-188). New York: Plenum.

Heward, W. L., \& Chance, P. (2010) (Orgs.). Special section: The human response to climate change: Ideas from behavior analysis. The Behavior Analyst, 33, 145-206. Recuperado de: http:// babat.org/wp-content/uploads/2016/10/TBAClimate-Change-Reprint.pdf

Leeming, E., Hansen, D., Alavosius, M., \& Reimer, D. (2013). Sustainability in the field: Lake Tahoe hospitality and environmental protection. Behavior and Social Issues, 22, 21-39. doi: 10.5210/bsi.v.22i0.4116

Leff, E. (2011). Complexidade, interdisciplinaridade e saber ambiental. Olhar do professor, 14, 309-335. doi: 10.5212/OlharProfr.v.14i2.0007

Loureiro, C. F. B. (2005). Complexidade e dialética: Contribuições à práxis política e emancipatória em educação ambiental. Educação e Sociedade, 26, 1473-1494. doi: 10.1590/S010173302005000400020

Loureiro, C. F. B. (2009). Trajetórias e fundamentos da educação ambiental. 3. ed. São Paulo: Cortez.

Matos, M. A. (1991). As categorias formais de comportamento verbal em Skinner. Anais da 21a Reunião Anual da Sociedade de Psicologia de Ribeirão Preto, Ribeirão Preto, São Paulo, Brasil. 
Matos, M. A. (1999). Análise funcional do comportamento. Estudos de Psicologia, 16, 8-18. doi: 10.1590/S0103-166X1999000300002

Matos, M. A. (2001). Comportamento governado por regras. Revista Brasileira de Terapia Comportamental e Cognitiva, 3(2), 51-66. Recuperado de http://pepsic.bvsalud.org/ scielo.php?script $=$ sci_arttext\&pid $=$ S1517$-55452001000200007 \& \operatorname{lng}=p t \& t \operatorname{lng}=p t$.

Moscardo, G., Woods, B., \& Saltzer, R. (2004). The role of interpretation in wildlife tourism. Em K. Higginbottom (Org.), Wildlife Tourism: Impacts, management and planning (pp. 231251). AltonaVic, Australia: Common Ground Publishing.

Pedrini, A. G. (2007). Ecoturismo, interpretação e educação ambientais: Consensuando conceitos. Anais do II Encontro Interdisciplinar de Ecoturismo em Unidades de Conservação, Itatiaia, Rio de Janeiro, Brasil.

Projeto Doces Matas/Grupo Temático de Interpretação Ambiental (2002). Manual de Introdução à Interpretação Ambiental. Belo Horizonte.

Sato, M. (2002). Educação Ambiental. São Carlos: RiMa.

Sidman M. (2000). Equivalence relations and the reinforcement contingency. Journal of the Experimental Analysis of Behavior, 74, 127-146. doi: 10.1901/jeab.2000.74-127

Silva, D. M. da (2012). A caracterização da Interpretação Ambiental pelo conteúdo das mensagens: Análise da atividade de um guia do Parque Estadual Mata dos Godoy (Londrinal $P R$ ) (Dissertação de mestrado). Universidade Estadual de Londrina, Londrina. Recuperado de: http://www.bibliotecadigital.uel.br/ document $/$ ?code $=$ vtls000169948.

Skinner, B. F. (1957). Verbal behavior. New York: Appleton-Century-Crofts.

Skinner, B. F. (1968). The technology of teaching. New York: Appleton-Century-Crofts.

Skinner, B. F. (1974). About behaviorism. New York: Alfred A. Knopf.

Skinner, B. F. (1984). Contingências do reforço: Uma análise teórica. Em Pavlov-Skinner da Coleção Os Pensadores (R. Azzi, \& R. Moreno, Trads.), São Paulo: Abril Cultural. (Trabalho original publicado em 1969)
Skinner, B. F. (2003). Ciência e comportamento humano. (J. C. Todorov, \& R. Azzi, Trads.). 11 ed. São Paulo: Martins Fontes. (Trabalho original publicado em 1953).

Smyth, J. C. (2006). Environment and education: A view of a changing scene. Environmental Education Research, 12, 247-264. doi: $10.1080 / 13504620600942642$

Tourinho, E. Z. (2003). A produção de conhecimento em psicologia: a análise do comportamento. Psicologia: Ciência e Profissão, 23(2), 30-41. doi: 10.1590/S1414-98932003000200006 Vasconcellos, J. M. de O. (2006). Educação e interpretação ambiental em unidades de conservação. Cadernos de Conservação, 3, 40-53.

\section{Informações do Artigo}

Histórico do artigo:

Submetido em: 28/07/2017

Aceito em: 15/03/2018

Editor associado: Felipe Leite 